\title{
Modeling the Conditional Volatility Asymmetry of Business Cycles in Four OECD Countries: A Multivariate GARCH Approach
}

\author{
Kin-Yip Ho ${ }^{\mathrm{a}}$, A.K. Tsui ${ }^{\mathrm{b}}$ and $\underline{\text { Z.Y. Zhang }}$ \\ ${ }^{a}$ College of Business and Economics, Australian National University, Australia \\ ${ }^{b}$ Department of Economics, National University of Singapore, Singapore \\ ${ }^{c}$ School of Accounting, Finance \& Economics, Edith Cowan University, Australia \\ Email: zhaoyong.zhang@ecu.edu.au
}

\begin{abstract}
There are many studies on the business cycle indicators in the past decades, but mostly focusing on the asymmetric and non-linear features of business cycles incorporated into the conditional mean equation rather than the conditional variance formulation. Recently, the hypothesis of volatility asymmetry in business cycle indicators has been re-examined by, for instance, Ho and Tsui (2003 and 2004) using univariate asymmetric power ARCH (APARCH) and EGARCH models. However, the main drawback of univariate GARCH analysis is that it fails to capture the co-movement of macroeconomic variables. These co-movement relationships are important issues emphasised by the business cycle researchers, yet not much work has been done on formally modelling co-movements of asymmetric conditional volatilities in the context of multivariate GARCH setting.
\end{abstract}

Our study extends the constant conditional correlation framework proposed by Bollerslev (1990) and the time-varying conditional correlation approach by Tse and Tsui (2002). We propose three new bivariate asymmetric GARCH models to accommodate the individual conditional heteroskedastic effects and the possibly varying conditional correlation relationships of asymmetric volatilities of the business cycles indicators in the selected OECD countries including Canada, Italy, the UK and the US. Using indices of industrial production as proxies for business cycles indicators, we detect statistically significant evidence of asymmetric conditional volatility in the UK and US. Additionally, we find that the conditional correlations are significantly time-varying, and that the strength of varying correlations may be linked to the degree of economic integration between the countries. These findings have the following implications:

- $\quad$ if business cycles are conditionally heteroskedastic and exhibit volatility asymmetry, then any theory without such properties is inadequate.

- the GARCH structure is consistent with the hypothesis of rational expectations in macroeconomics as rational economic agents make decisions based on all available information (see Hong and Lee, 2001 for details).

- $\quad$ since movements in the financial markets are inextricably linked to the overall health of the economy, adequate accommodation of macroeconomic uncertainty such as conditional volatilities of business cycles would help researchers understand more about the causes of changes in financial market volatilities, and

- $\quad$ it is vital to understand the domestic macroeconomic policy implications of asymmetric volatility and the corresponding policy co-ordinations among major international trading partners.

Keywords: Business Cycle Non-linearities; Constant Correlations; Index of Industrial Production; Multivariate Asymmetric GARCH; Varying-Correlations 


\section{INTRODUCTION}

In the past two decades various approaches to studying properties of the business cycle indicators have been conducted by researchers such as Neftci (1984), Luukkonen and Terasvirta (1991), Terasvirta and Anderson (1992) and Sichel (1989). Most of these studies concentrate on the asymmetric and non-linear features of business cycles incorporated into the conditional mean equation rather than the conditional variance formulation. Hamori (2000) applies the exponential generalized autoregressive conditional heteroskedastic (EGARCH) model proposed by Nelson (1991) on the real GDP growth rates of Japan, UK and US, and finds no statistically significant evidence of volatility asymmetry. Recently, the hypothesis of volatility asymmetry in business cycle indicators is re-examined by Ho and Tsui (2003 and 2004) using univariate asymmetric power ARCH (APARCH) and EGARCH models. In contrast, they detect significant asymmetric effects in the highly developed countries like Canada, UK and US, and also in the relatively less developed countries like Hong Kong, Taiwan and China, respectively. However, the main drawback of univariate GARCH analysis is that it fails to capture the co-movement of macroeconomic variables which undoubtedly are important issues in modeling business cycle. Diebold and Rudebusch (1996) argue that business cycle models should take into account the co-movement of macroeconomic variables and their regime-switching behaviour. In addition, features of international co-movements and transmission of business cycles have also received much attention recently (see Frankel and Rose, 1998, A'Hearn and Ulrich, 2001, and Choe, 2001). These studies, however, mainly focus on formulating ad-hoc structures to capture co-movements of certain macroeconomic variables. Little work has been done on formally modelling co-movements of asymmetric conditional volatilities in the context of multivariate GARCH setting.

In this paper, we propose three new bivariate asymmetric GARCH models to accommodate the individual conditional heteroskedastic effects and the possibly varying conditional correlation relationships of asymmetric volatilities of the business cycles indicators in the selected OECD countries including Canada, Italy, the UK and the US. In particular, we extend the work by Ding et al (1993), Sentana (1995), and Tse and Tsui (2002) to incorporate the possibly asymmetric effects of the business cycles shocks on a specific country. This study has important implications. First, if business cycles are conditionally heteroskedastic and exhibit volatility asymmetry, then any theory without such properties is inadequate. Second, the GARCH structure is consistent with the hypothesis of rational expectations in macroeconomics as rational economic agents make decisions based on all available information (see Hong and Lee, 2001 for details). Third, since movements in the financial markets are inextricably linked to the overall health of the economy, adequate accommodation of macroeconomic uncertainty such as conditional volatilities of business cycles would help researchers understand more about the causes of changes in financial market volatilities. Fourth, it is vital to understand the domestic macroeconomic policy implications of asymmetric volatility and the corresponding policy co-ordinations among major international trading partners.

The rest of the paper is organized as follows. Section 2 explains the methodology of the proposed models and their advantages. Section 3 describes the data used in this study. Section 4 highlights some empirical issues and presents the estimation results. Section 5 provides some concluding remarks.

\section{METHODOLOGY AND THE MODEL}

The success of Engle's (1982) ARCH and Bollerslev's (1986) GARCH models in characterising volatility dynamics has motivated researchers to make extensions to the multivariate context. The major problem with multivariate generalisation is that the number of parameters to be estimated is inevitably increased, thereby complicating specifications of the conditional variance-covariance matrix (see Bera and Higgins, 1993, and Tse, 2000). To ensure the variance and covariance matrix is positive-definite, Engle and Kroner (1995) propose the BEKK model. One disadvantage of this model is that the parameters cannot be easily interpreted, and their net effects on the conditional variances and co-variances are not readily apparent. More recently, Tse and Tsui (2002) develop a varying-correlation MGARCH (VC-MGARCH) model to incorporate dynamic correlations and yet satisfy the positive-definite condition. One major advantage of VC-MGARCH is that it retains the usual interpretation of the univariate $\mathrm{GARCH}$ equation and is more manageable than that of the BEKK model. In addition, the VC-MGARCH model nests the CC-MGARCH model and therefore provides an indirect way of testing the constant correlations hypothesis. Moreover, Tse and Tsui (2002) report that the VC-MGARCH model compares favourably against the BEKK model based on some empirical studies of the Singapore and Hong Kong stock markets. However, the VC-MGARCH approach does not explicitly model the possible existence of volatility asymmetry, whereby a negative return shock may generate greater impact on future volatilities compared with a positive shock of the same magnitude. To rectify such discrepancies, we propose three new bivariate asymmetric GARCH models based on a synthesis of the methodologies of Ding et al (1993), Sentana (1995) and Tse and Tsui (2002). They are, namely, the 
VC-Quadratic GARCH (VC-QGARCH) model, the VC-Leveraged GARCH (VC-LGARCH) model, and the VC-Threshold GARCH (VC-TGARCH) model, respectively. These specifications enable the concurrent modelling of conditional volatility asymmetry and time-varying conditional correlations. They also nest various popular versions of asymmetric GARCH models. As little study has been concentrated on comovements of the conditional heteroskedasticity of macroeconomic variables, we shall apply the proposed models to examine the possible evidence of volatility asymmetry and time-changing conditional correlation in the overall Index of Industrial Production (IIP) of Canada, Italy, the United Kingdom and the United States, respectively.

Denoting $Y_{i t}$ as the $i^{\text {th }}$ variable of interest, we define the growth rate (in percentage) computed on a continuously compounding basis as

$$
y_{i t}=\log \left(\frac{Y_{i t}}{Y_{i t-1}}\right) \times 100
$$

We assume that the conditional mean equation for each variable is effectively captured by an autoregressive filter of order $\mathrm{k}$ :

$$
\mathrm{y}_{\mathrm{it}}=\pi_{0}+\sum_{j=1}^{k} \pi_{\mathrm{j}} \mathrm{y}_{\mathrm{it}-\mathrm{j}}+\varepsilon_{\mathrm{it}}
$$

where $\varepsilon_{\mathrm{it}}$ is the identically and independently distributed error term. The structure of $\varepsilon_{\mathrm{it}}$ is set up as

$$
\varepsilon_{\mathrm{it}}=\mathrm{s}_{\mathrm{it}} \mathrm{e}_{\mathrm{it}}, \quad \text { where } \mathrm{e}_{\mathrm{it}} \sim \mathrm{N}(0,1)
$$

Note that $s_{i t}$ is associated with the conditional variance equation under three different specifications, namely, the QGARCH, LGARCH and TGARCH models, respectively. These specifications are less restrictive since they nest several versions of popular GARCH models.

The QGARCH(1,1) model proposed by Sentana (1995) is specified as

$$
\mathrm{s}_{\mathrm{it}}=\eta+\gamma \varepsilon_{\mathrm{it}-1}+\alpha \varepsilon_{\mathrm{it}-1}^{2}+\mathrm{s}_{\mathrm{it}-1}
$$

where $\gamma$ is the asymmetric coefficient. It represents the most general quadratic version possible within the $\mathrm{ARCH}$ class and encompasses many existing quadratic variance functions. The QGARCH model provides a very neat way of calibrating and testing for dynamic asymmetries in the conditional variance function without departing significantly from the standard specification.

The LGARCH and TGARCH models proposed by Ding et al (1993) share the following structure:

$$
\mathrm{s}_{\mathrm{it}}{ }^{\delta}=\eta+\alpha\left(\left|\varepsilon_{\mathrm{it}-1}\right|-\gamma \varepsilon_{\mathrm{it}-1}\right)^{\delta}+\beta \mathrm{s}_{\mathrm{it}-1} \delta
$$

When $\delta=2$, this is the $\operatorname{LGARCH}(1,1)$ model which nests the GJR specification. According to Engle and $\mathrm{Ng}$ (1993), the GJR formulation is the best parametric model compared with other models like EGARCH. Alternatively, when $\delta=1$, it becomes the $\operatorname{TGARCH}(1,1)$ model, which incorporates an asymmetric version of the Taylor/Schwert model and Zakoian's (1994) Threshold ARCH (TARCH) model.

Intuitively, the VC-MGARCH model proposed by Tse and Tsui (2002) has a time-varying conditional correlation structure resembling a standard Box-Jenkins type of ARMA structure. In particular, the conditional correlations formulation in a bivariate VC-MGARCH model is

$\rho_{\mathrm{t}}=\left(1-\theta_{1}-\theta_{2}\right) \rho+\theta_{1} \rho_{\mathrm{t}-1}+\theta_{2} \psi_{\mathrm{t}-1}$

where $\left(1-\theta_{1}-\theta_{2}\right) \rho$ is the time-invariant conditional correlation coefficient, $\theta_{1}$ and $\theta_{2}$ are assumed to be nonnegative and sum up to less than 1 , and $\psi_{\mathrm{t}-1}$ is specified as

$$
\psi_{t-1}=\frac{\sum_{n=1}^{2} e_{1, t-n} e_{2, t-n}}{\sqrt{\left(\sum_{n=1}^{2} e_{1, t-n}^{2}\right)\left(\sum_{n=1}^{2} e_{2, t-n}^{2}\right)}}
$$


Ignoring the constant term and assuming normality, the conditional log likelihood function of the sample of size $n$ is

$$
L=-\frac{1}{2} \sum_{t}\left(\log \left(1-\rho_{t}^{2}\right)+\frac{e_{1, t}^{2}+e_{2, t}^{2}-2 \rho_{t} e_{1, t} e_{2, t}}{\left(1-\rho_{t}^{2}\right)}\right)
$$

The total number of parameters is 11 for a bivariate asymmetric GARCH model with varying correlations, and this number always exceeds that of Bollerslev's (1990) constantcorrelation model by 2 . In fact, the $\mathrm{CC}$ MGARCH model is nested within the VCMGARCH model by restricting $\theta_{1}$ and $\theta_{2}$ to zero.

\section{EMPIRICAL ANALYSIS}

\subsection{Data Description}

Our data sets comprise 444 monthly indices of industrial production (IIP) series for Canada, Italy, the United Kingdom and the United States. These seasonally adjusted data sets are culled from the SourceOECD, covering the period from January 1961 to December 1997. There are four reasons to justify the preference of IIP to GDP as proxies for business cycle indicators. First, IIP series is widely used by many researchers (see Blanchard and Quah, 1989, Terasvirta and Anderson, 1992, and A'Hearn and Woitek, 2001). Second, according to OECD's Main Economic Indicators, the series is used as the major reference for aggregate economic activity in Canada, Italy, the United Kingdom and the United States. Prompt availability of the series on a monthly basis and its closely related cyclical profiles with GDP are the main reasons for its popularity. Third, the chosen four OECD countries have included mining, manufacturing, and electricity, gas and water in IIP series, thereby ensuring comparability of data sets across countries. In contrast, not all OECD countries have implemented the System of Nation Accounts (SNA) promulgated by the United Nations in 1993 as the basis for compiling GDP figures. For example, real GDP estimates produced by the US are of the chain volume type, whereas those by Canada and UK are based on the more traditional fixedbase volume estimates. Hence, one should avoid such aberrations that may affect the related estimation and statistical inference. Finally, a larger data set is required to facilitate computational convergence in the estimation of model parameters. On balance, the monthly IIP series are preferred to the quarterly GDP as reasonable proxies for the business cycles indicators.

We first assess the statistical features of the IIP series in these economies and report the results in Table 1. As can be see, all growth rates of IIP series (in percentage) are negatively skewed and leptokurtic. In particular, the UK has the highest kurtosis, about 3 times than that of a standard normal distribution. On the other hand, the skewness is highest for the US, indicating that negative growth rates are more prevalent. Such nonnormal properties are also captured by the highly significant Jarque-Bera test statistics reported in Panel B. As such, appropriate GARCH models seem adequate to accommodate the statistical feature of leptokurtosis. This is further reinforced by the detection of conditional heteroskedasticity. As indicated in Panel D of Table 1, the McLeod-Li and the ARCH LM test results are significant at the 5\% level. In addition, the nonparametric BDS and runs tests are conducted as diagnostic checks. It is noted that the BDS test proposed by Brock et al (1996) has power against a variety of possible deviations from independence. As can be observed from Panels F and G, the BDS tests unequivocally reject the hypothesis that IIP series are identically and independently distributed. The runs tests based on the squared and absolute series of the growth rates of Italy, UK and US are statistically significant at the 5\% level, indicating the presence of conditional heteroskedasticity. Panel G of Table 1 displays the QARCH(q)-LM test statistics, which are computed by regressing the squared growth rate $\left(r_{t}^{2}\right)$ on a constant, the first q lags of $r_{t}^{2}$, the cross products of the form $\left(r_{t}\right.$ $\left.{ }_{i} r_{t-j}\right)$, and the first q lags of the growth rate $r_{t}$, respectively. Except for Canada, the LM tests for Italy, UK and US are all significant at the 5\% level, indicating the presence of asymmetric conditional volatilities. We also launch a more powerful one-sided QARCH (q)-LM test proposed by Sentana (1995), which is constructed by summing up squares of $t$-ratios of the respective regression coefficients. Though not reported here, the test 
Ho et al., Modeling the Conditional Volatility Asymmetry of Business Cycles in Four OECD Countries

results are similar to those of the two-sided LM tests. We have also conducted the augmented Dickey Fuller (ADF) and Phillips-Perron (PP) tests to ensure that our data sets are stationary. The Ljung-Box Q-statistic and the Breusch-Godfrey (BG) diagnostic checks for residuals obtained from the ADF regression equation are statistically insignificant at the 5\% level, implying that the residuals are approximately white noise (the results are available upon request).

\subsection{Empirical Results}

Tables 2-4 report the estimation results of the VC-QGARCH, VC-LGARCH, and VC-TGARCH models. First, the estimated coefficient of volatility asymmetry is significant at the 5\% level for Canada, the UK, and the US in all three models. For the UK and the US, the estimated coefficients suggest that negative shocks have a greater impact on future volatilities than positive shocks of the same magnitude. This is consistent with Ho and Tsui (2003), who have detected significantly negative volatility asymmetry in the real GDP of the UK and the US. Second, the estimated coefficient of volatility asymmetry for Canada indicates that positive rather than negative shocks of IIP growth rates that increase future volatilities. The results provide evidence that it is premature to conclude that business cycle indicators do not exhibit volatility asymmetry.

\begin{tabular}{|c|c|c|c|c|c|c|c|c|c|c|c|c|c|}
\hline \multirow[b]{3}{*}{ Jountry 1} & \multirow[b]{3}{*}{\begin{tabular}{|l} 
Country 2 \\
\end{tabular}} & \multicolumn{8}{|c|}{ Conditional Variance } & \multicolumn{4}{|c|}{ Conditional Correlations } \\
\hline & & \multirow{2}{*}{\multicolumn{4}{|c|}{ Country 1}} & \multicolumn{4}{|c|}{ Country2 } & \multicolumn{3}{|c|}{ VC-QGARCH } & \multirow{2}{*}{\begin{tabular}{|l|} 
CC \\
$\rho^{*}$ \\
\end{tabular}} \\
\hline & & & & & & $\eta_{2}$ & $\alpha_{2}$ & $\beta_{2}$ & $\gamma_{2}$ & $\rho$ & $\theta_{1}$ & $\theta_{2}$ & \\
\hline Janada & US & $\begin{array}{l}1.2600 \\
(0.0022)\end{array}$ & \begin{tabular}{|l|}
0.0249 \\
$(0.0133)$ \\
\end{tabular} & $\begin{array}{l}0.9740 \\
(0.0123)\end{array}$ & $\begin{array}{l}n \\
0.2410 \\
(0.0079)\end{array}$ & \begin{tabular}{|l|}
5.0977 \\
$(0.0006)$
\end{tabular} & \begin{tabular}{|l|}
0.0330 \\
$(0.0229)$ \\
\end{tabular} & $\begin{array}{l}0.9666 \\
(0.0188) \\
\end{array}$ & \begin{tabular}{|l|}
-0.6246 \\
$(0.0071)$ \\
\end{tabular} & $\begin{array}{l}0.3490 \\
(0.0374) \\
\end{array}$ & \begin{tabular}{|l|l|}
0.7391 \\
$(0.0182)$ \\
\end{tabular} & \begin{tabular}{|l|}
0.0103 \\
$(0.0045)$ \\
\end{tabular} & $\begin{array}{l}0.3447 \\
(0.0406) \\
\end{array}$ \\
\hline$\overline{\text { Sanada }}$ & Italy & $\begin{array}{l}1.2561 \\
(0.0008) \\
\end{array}$ & \begin{tabular}{|l|}
0.0291 \\
$(0.0141)$ \\
\end{tabular} & $\begin{array}{l}0.9700 \\
(0.0128) \\
\end{array}$ & \begin{tabular}{|l|}
0.2196 \\
$(0.0042)$ \\
\end{tabular} & \begin{tabular}{|l|}
5.2310 \\
$(0.0003)$ \\
\end{tabular} & \begin{tabular}{|l|}
0.1243 \\
$(0.0572)$ \\
\end{tabular} & $\begin{array}{l}0.8912 \\
(0.0422) \\
\end{array}$ & \begin{tabular}{|l|}
0.0449 \\
$(0.0429)$ \\
\end{tabular} & \begin{tabular}{|l|}
0.1230 \\
$(0.0287)$ \\
\end{tabular} & \begin{tabular}{|l|}
0.4019 \\
$(0.0066)$ \\
\end{tabular} & $\begin{array}{l}0.0706 \\
(0.0321) \\
\end{array}$ & \begin{tabular}{|l|}
0.1208 \\
$(0.0455)$ \\
\end{tabular} \\
\hline Janada & UK & $\begin{array}{l}1.2296 \\
(0.0096) \\
\end{array}$ & $\begin{array}{l}0.0294 \\
(0.0195) \\
\end{array}$ & $\begin{array}{l}0.9698 \\
(0.0178)\end{array}$ & $\begin{array}{l}0.2348 \\
(0.0167) \\
\end{array}$ & $\begin{array}{l}2.1385 \\
(0.0054) \\
\end{array}$ & \begin{tabular}{|l|}
0.1482 \\
$(0.1045)$ \\
\end{tabular} & $\begin{array}{l}0.8801 \\
(0.0670)\end{array}$ & \begin{tabular}{|l|}
-0.1270 \\
$(0.0347)$ \\
\end{tabular} & \begin{tabular}{|l|}
0.1024 \\
$(0.0403)$ \\
\end{tabular} & \begin{tabular}{|l|}
0.9451 \\
$(0.0683)$ \\
\end{tabular} & $\begin{array}{l}0.0036 \\
(0.0006)\end{array}$ & $\begin{array}{l}0.1021 \\
(0.0458) \\
\end{array}$ \\
\hline taly & UK & $\begin{array}{l}1.2296 \\
(0.0015)\end{array}$ & \begin{tabular}{|l|l|}
0.1382 \\
$(0.0882)$
\end{tabular} & $\begin{array}{l}0.8804 \\
(0.0641)\end{array}$ & $\begin{array}{l}-0.0362 \\
(0.0400)\end{array}$ & $\begin{array}{l}2.1385 \\
(0.0016) \\
\end{array}$ & $\begin{array}{l}0.1506 \\
(0.0949) \\
\end{array}$ & $\begin{array}{l}0.8781 \\
(0.0606)\end{array}$ & \begin{tabular}{|l|}
-0.2248 \\
$(0.0184)$
\end{tabular} & \begin{tabular}{|l|}
0.2418 \\
$(0.0639)$
\end{tabular} & \begin{tabular}{|l}
0.9641 \\
$(0.0252)$
\end{tabular} & $\begin{array}{l}0.0208 \\
(0.0048) \\
\end{array}$ & $\begin{array}{l}0.1921 \\
(0.0472) \\
\end{array}$ \\
\hline 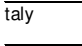 & US & $\begin{array}{l}2.1937 \\
(0.0029) \\
\end{array}$ & $\begin{array}{l}0.1298 \\
(0.0900) \\
\end{array}$ & $\begin{array}{l}0.8870 \\
(0.0661)\end{array}$ & $\begin{array}{l}-0.0702 \\
(0.0702)\end{array}$ & $\begin{array}{l}1.4840 \\
(0.0049) \\
\end{array}$ & \begin{tabular}{|l|}
0.0362 \\
$(0.0253)$ \\
\end{tabular} & $\begin{array}{l}0.9637 \\
(0.0208)\end{array}$ & \begin{tabular}{|l|}
-0.9621 \\
$(0.0040)$ \\
\end{tabular} & \begin{tabular}{|l|}
0.1570 \\
$(0.0408)$
\end{tabular} & \begin{tabular}{|l|}
0.8258 \\
$(0.0489)$ \\
\end{tabular} & $\begin{array}{l}0.0261 \\
(0.0068)\end{array}$ & \begin{tabular}{|l|}
0.1596 \\
$(0.0453)$ \\
\end{tabular} \\
\hline$\overline{J K}$ & US & $\begin{array}{l}1.2208 \\
(0.0009) \\
\end{array}$ & \begin{tabular}{|l|}
0.1482 \\
$(0.1015)$
\end{tabular} & $\begin{array}{l}0.8798 \\
(0.0649)\end{array}$ & $\begin{array}{l}-0.1286 \\
(0.0481)\end{array}$ & $\begin{array}{l}5.1453 \\
(0.0004)\end{array}$ & $\begin{array}{l}0.0360 \\
(0.0284)\end{array}$ & $\begin{array}{l}0.9639 \\
(0.0237)\end{array}$ & $\begin{array}{l}-0.8091 \\
(0.0062) \\
\end{array}$ & $\begin{array}{l}0.1695 \\
(0.0282) \\
\end{array}$ & \begin{tabular}{|l|}
0.9588 \\
$(0.0421)$
\end{tabular} & $\begin{array}{l}0.0308 \\
(0.0151)\end{array}$ & $\begin{array}{l}0.1735 \\
(0.0449) \\
\end{array}$ \\
\hline
\end{tabular}

QGARCH) while $\rho^{\star}$ is the constant conditional correlation coefficient.

\begin{tabular}{|c|c|c|c|c|c|c|c|c|c|c|c|c|c|}
\hline \multirow[b]{3}{*}{ Zountry 1} & \multirow[b]{3}{*}{ Country 2} & \multicolumn{8}{|c|}{ Conditional Variance } & \multicolumn{4}{|c|}{ Conditional Correlations } \\
\hline & & \multicolumn{4}{|c|}{ Country 1} & \multicolumn{4}{|c|}{ Country 2} & \multicolumn{3}{|c|}{ VC-LGARCH } & \multirow{2}{*}{$\begin{array}{l}\text { CC } \\
\rho^{*}\end{array}$} \\
\hline & & $\eta_{1}$ & $\alpha_{1}$ & $\beta_{1}$ & $\gamma_{1}$ & $\eta_{2}$ & $\alpha_{2}$ & $\beta_{2}$ & $\gamma_{2}$ & $\rho$ & $\theta_{1}$ & $\theta_{2}$ & \\
\hline Janada & US & $\begin{array}{l}1.2600 \\
(0.0026)\end{array}$ & \begin{tabular}{|l}
0.0253 \\
$(0.0259)$
\end{tabular} & $\begin{array}{ll}0.9737 \\
(0.0227)\end{array}$ & $\begin{array}{c}-0.0073 \\
(0.0013)\end{array}$ & $\begin{array}{l}5.1000 \\
(0.0003)\end{array}$ & $\begin{array}{l}0.0353 \\
(0.0171)\end{array}$ & $\begin{array}{l}0.9498 \\
(0.0180)\end{array}$ & \begin{tabular}{|l}
0.5871 \\
$(0.0009)$
\end{tabular} & $\begin{array}{l}0.3437 \\
(0.0093)\end{array}$ & \begin{tabular}{|l|l}
0.7324 \\
$(0.0006)$
\end{tabular} & $\begin{array}{l}0.0131 \\
(0.0052)\end{array}$ & $\begin{array}{l}0.3381 \\
(0.0102)\end{array}$ \\
\hline Janada & Italy & \begin{tabular}{|l|}
1.2560 \\
$(0.0005)$
\end{tabular} & \begin{tabular}{|l|}
0.0297 \\
$(0.0529)$
\end{tabular} & \begin{tabular}{|l|}
0.9694 \\
$(0.0491)$
\end{tabular} & $\begin{array}{l}-0.0197 \\
(0.0087)\end{array}$ & $\begin{array}{l}5.2300 \\
(0.0008)\end{array}$ & $\begin{array}{l}0.1174 \\
(0.0243)\end{array}$ & \begin{tabular}{|l|l|}
0.8960 \\
$(0.0175)$
\end{tabular} & \begin{tabular}{|l|l|}
0.0449 \\
$(0.0719)$
\end{tabular} & $\begin{array}{l}0.1220 \\
(0.0212)\end{array}$ & \begin{tabular}{|l|}
0.4044 \\
$(0.0071)$
\end{tabular} & $\begin{array}{l}0.0714 \\
(0.0227)\end{array}$ & $\begin{array}{l}0.1199 \\
(0.0012)\end{array}$ \\
\hline Janada & UK & \begin{tabular}{|l|}
1.2296 \\
$(0.0041)$
\end{tabular} & \begin{tabular}{|l|}
0.0305 \\
$(0.0359)$
\end{tabular} & \begin{tabular}{|l|}
0.9686 \\
$(0.0339)$ \\
\end{tabular} & $\begin{array}{l}-0.0371 \\
(0.0026)\end{array}$ & $\begin{array}{l}2.1385 \\
(0.0026)\end{array}$ & $\begin{array}{l}0.1260 \\
(0.0612)\end{array}$ & \begin{tabular}{|l}
0.8904 \\
$(0.0425)$
\end{tabular} & \begin{tabular}{|l|}
0.1267 \\
$(0.0568)$
\end{tabular} & \begin{tabular}{|l|}
0.1016 \\
$(0.0262)$
\end{tabular} & \begin{tabular}{|l|}
0.9493 \\
$(0.0121)$
\end{tabular} & $\begin{array}{l}0.0039 \\
(0.0010)\end{array}$ & $\begin{array}{l}0.1012 \\
(0.0202)\end{array}$ \\
\hline taly & UK & \begin{tabular}{|l|}
1.2296 \\
$(0.0012)$ \\
\end{tabular} & \begin{tabular}{|l|l|}
0.1309 \\
$(0.0605)$ \\
\end{tabular} & \begin{tabular}{|l}
0.8855 \\
$(0.0429)$ \\
\end{tabular} & $\begin{array}{l}0.0362 \\
(0.3429) \\
\end{array}$ & $\begin{array}{l}2.1385 \\
(0.0016) \\
\end{array}$ & $\begin{array}{l}0.1292 \\
(0.0626) \\
\end{array}$ & \begin{tabular}{|l|l|}
0.8879 \\
$(0.0434)$ \\
\end{tabular} & \begin{tabular}{|l}
0.1248 \\
$(0.0457)$ \\
\end{tabular} & \begin{tabular}{|l|l|}
0.2394 \\
$(0.0316)$ \\
\end{tabular} & \begin{tabular}{|l|}
0.9643 \\
$(0.0223)$ \\
\end{tabular} & $\begin{array}{l}0.0208 \\
(0.0151)\end{array}$ & $\begin{array}{l}0.1900 \\
(0.0217)\end{array}$ \\
\hline taly & US & $\begin{array}{l}2.1937 \\
(0.0089)\end{array}$ & \begin{tabular}{|l}
0.1238 \\
$(0.0995)$
\end{tabular} & \begin{tabular}{|l|l}
0.8912 \\
$(0.0737)$
\end{tabular} & $\begin{array}{l}0.0281 \\
(0.1884)\end{array}$ & $\begin{array}{l}1.4840 \\
(0.0083)\end{array}$ & $\begin{array}{l}0.0401 \\
(0.0295)\end{array}$ & $\begin{array}{l}0.9442 \\
(0.0336)\end{array}$ & \begin{tabular}{|l|}
0.5891 \\
$(0.0944)$
\end{tabular} & $\begin{array}{l}0.1500 \\
(0.0438)\end{array}$ & \begin{tabular}{|l|}
0.8518 \\
$(0.0627)$
\end{tabular} & $\begin{array}{l}0.0177 \\
(0.0056)\end{array}$ & $\begin{array}{l}0.1536 \\
(0.0400)\end{array}$ \\
\hline $\mathrm{JK}$ & US & \begin{tabular}{|l|l}
1.2208 \\
$(0.0017)$
\end{tabular} & \begin{tabular}{|l|}
0.1238 \\
$(0.0939)$
\end{tabular} & \begin{tabular}{|l|}
0.8915 \\
$(0.0651)$
\end{tabular} & $\begin{array}{l}0.1262 \\
(0.0119) \\
\end{array}$ & $\begin{array}{l}5.1453 \\
(0.0007)\end{array}$ & $\begin{array}{l}0.0396 \\
(0.0288)\end{array}$ & \begin{tabular}{|l|}
0.9440 \\
$(0.0331)$
\end{tabular} & \begin{tabular}{|l|l}
0.6047 \\
$(0.0750)$
\end{tabular} & \begin{tabular}{|l|l}
0.1649 \\
$(0.0314)$
\end{tabular} & \begin{tabular}{|l|}
0.9593 \\
$(0.0368)$
\end{tabular} & $\begin{array}{l}0.0286 \\
(0.0168) \\
\end{array}$ & $\begin{array}{l}0.1600 \\
(0.0312)\end{array}$ \\
\hline
\end{tabular}
Note: The Bollerslev-Wooldridge robust, heteroskedastic-consistent standard errors are reported in parentheses. CC refers to the constant conditional correlations model (CCLGARCH) while $\rho^{\star}$ is the constant conditional correlation coefficient.

\begin{tabular}{|c|c|c|c|c|c|c|c|c|c|c|c|c|c|}
\hline \multirow[b]{3}{*}{ Country 1} & \multirow[b]{3}{*}{ Country 2} & \multicolumn{8}{|c|}{ Conditional Variance } & \multicolumn{4}{|c|}{ Conditional Correlations } \\
\hline & & \multicolumn{4}{|l|}{\begin{tabular}{|l|} 
Country 1 \\
\end{tabular}} & \multicolumn{4}{|l|}{ Country 2} & \multicolumn{3}{|c|}{ VC-TGARCH } & \multirow{2}{*}{$\frac{C C}{\rho^{*}}$} \\
\hline & & $\eta_{1}$ & $\alpha_{1}$ & $\beta_{1}$ & $\gamma_{1}$ & $\eta_{2}$ & $\alpha_{2}$ & $\beta_{2}$ & $\gamma_{2}$ & $\rho$ & $\theta_{1}$ & $\theta_{2}$ & \\
\hline Canada & US & $\begin{array}{l}1.1805 \\
(0.0015) \\
\end{array}$ & $\begin{array}{l}0.3877 \\
(0.0863) \\
\end{array}$ & \begin{tabular}{|l|}
0.9233 \\
$(0.0158)$ \\
\end{tabular} & \begin{tabular}{|l|}
-0.2955 \\
$(0.0667)$ \\
\end{tabular} & $\begin{array}{l}4.5366 \\
(0.0004) \\
\end{array}$ & $\begin{array}{l}0.3731 \\
(0.1033) \\
\end{array}$ & $\begin{array}{l}0.9292 \\
(0.0186) \\
\end{array}$ & $\begin{array}{l}0.1342 \\
(0.0620) \\
\end{array}$ & $\begin{array}{l}0.9647 \\
(0.0130) \\
\end{array}$ & \begin{tabular}{|l|}
0.6322 \\
$(0.0525)$ \\
\end{tabular} & \begin{tabular}{|l|}
0.0080 \\
$(0.0053)$ \\
\end{tabular} & $\begin{array}{l}0.9456 \\
(0.0025) \\
\end{array}$ \\
\hline Canada & Italy & $\begin{array}{l}1.1812 \\
(0.0021)\end{array}$ & $\begin{array}{l}0.2965 \\
(0.0763)\end{array}$ & $\begin{array}{l}0.9243 \\
(0.0157)\end{array}$ & \begin{tabular}{|c|}
-0.2761 \\
$(0.0730)$
\end{tabular} & $\begin{array}{l}4.5363 \\
(0.0025)\end{array}$ & $\begin{array}{l}0.7752 \\
(0.0669)\end{array}$ & $\begin{array}{l}0.8152 \\
(0.0240)\end{array}$ & $\begin{array}{l}0.0165 \\
(0.0322)\end{array}$ & $\begin{array}{l}0.8975 \\
(0.0384)\end{array}$ & $\begin{array}{l}0.5435 \\
(0.0112)\end{array}$ & \begin{tabular}{|l|}
0.0026 \\
$(0.0082)$
\end{tabular} & $\begin{array}{l}0.8930 \\
(0.0254)\end{array}$ \\
\hline Canada & UK & $\begin{array}{l}1.1805 \\
(0.0026) \\
\end{array}$ & $\begin{array}{l}0.5330 \\
(0.0992) \\
\end{array}$ & $\begin{array}{l}0.9327 \\
(0.0118) \\
\end{array}$ & \begin{tabular}{|c|}
-0.2578 \\
$(0.0703)$ \\
\end{tabular} & $\begin{array}{l}4.5359 \\
(0.0002)\end{array}$ & $\begin{array}{l}0.8282 \\
(0.0625)\end{array}$ & $\begin{array}{l}0.9023 \\
(0.0222) \\
\end{array}$ & $\begin{array}{l}0.2576 \\
(0.1056)\end{array}$ & $\begin{array}{l}0.9635 \\
(0.0133) \\
\end{array}$ & $\begin{array}{l}0.6982 \\
(0.0795) \\
\end{array}$ & \begin{tabular}{|l|}
0.0037 \\
$(0.0024)$ \\
\end{tabular} & $\begin{array}{l}0.9563 \\
(0.0023) \\
\end{array}$ \\
\hline Italy & UK & $\begin{array}{l}5.2332 \\
(0.0002)\end{array}$ & $\begin{array}{l}0.3279 \\
(0.0369) \\
\end{array}$ & $\begin{array}{l}0.7702 \\
(0.0284) \\
\end{array}$ & \begin{tabular}{|l|}
0.0916 \\
$(0.0798)$ \\
\end{tabular} & $\begin{array}{l}5.0051 \\
(0.0016) \\
\end{array}$ & $\begin{array}{l}0.7970 \\
(0.0544)\end{array}$ & $\begin{array}{l}0.8247 \\
(0.0265)\end{array}$ & $\begin{array}{l}0.1202 \\
(0.0124)\end{array}$ & $\begin{array}{l}0.9892 \\
(0.0040)\end{array}$ & $\begin{array}{l}0.6790 \\
(0.0426) \\
\end{array}$ & \begin{tabular}{|l|}
0.0022 \\
$(0.0013)$ \\
\end{tabular} & $\begin{array}{l}0.9811 \\
(0.0123) \\
\end{array}$ \\
\hline Italy & US & $\begin{array}{l}5.2312 \\
(0.0014)\end{array}$ & $\begin{array}{l}0.4108 \\
(0.0388)\end{array}$ & $\begin{array}{l}0.8175 \\
(0.0240) \\
\end{array}$ & \begin{tabular}{|c|}
-0.0325 \\
$(0.2045)$ \\
\end{tabular} & $\begin{array}{l}5.0055 \\
(0.0045)\end{array}$ & $\begin{array}{l}0.8204 \\
(0.0596)\end{array}$ & $\begin{array}{l}0.8929 \\
(0.0168) \\
\end{array}$ & $\begin{array}{l}0.2986 \\
(0.0941) \\
\end{array}$ & $\begin{array}{l}0.9728 \\
(0.0088)\end{array}$ & $\begin{array}{l}0.2513 \\
(0.0363) \\
\end{array}$ & \begin{tabular}{|l|}
0.0016 \\
$(0.0038)$ \\
\end{tabular} & $\begin{array}{l}0.9710 \\
(0.0056)\end{array}$ \\
\hline UK & US & $\begin{array}{l}1.2673 \\
(0.0008)\end{array}$ & $\begin{array}{l}0.5694 \\
(0.0973)\end{array}$ & $\begin{array}{l}0.8891 \\
(0.0229) \\
\end{array}$ & \begin{tabular}{|l|}
0.2507 \\
$(0.1146)$ \\
\end{tabular} & $\begin{array}{l}5.0797 \\
(0.0003)\end{array}$ & $\begin{array}{l}0.4933 \\
(0.0777) \\
\end{array}$ & $\begin{array}{l}0.9034 \\
(0.0141)\end{array}$ & $\begin{array}{l}0.3124 \\
(0.0779) \\
\end{array}$ & $\begin{array}{l}0.9496 \\
(0.0183)\end{array}$ & $\begin{array}{l}0.7574 \\
(0.0343) \\
\end{array}$ & \begin{tabular}{|l|}
0.0050 \\
$(0.0048)$
\end{tabular} & $\begin{array}{l}0.9372 \\
(0.0145)\end{array}$ \\
\hline
\end{tabular}

TGARCH) while $\rho^{*}$ is the constant conditional correlation coefficient.

Most parameter estimates of the time-varying conditional correlation coefficient equation are significant at the 5\% level, indicating that dynamic correlations probably exist among the 4 OECD countries. Additionally, the estimates of the time-invariant component of the correlation coefficient equation, $\rho$, are significantly positive and broadly similar to those estimates from the constant conditional correlations models. The finding of positive correlations is consistent with other empirical studies such as Choe (2001), who observes that in an equilibrium-business cycle framework, the international co-movement of cyclical variation in income is positively correlated across countries. In particular, the pattern of conditional correlations and the magnitudes of estimated $\rho$ differ among the 6 country pairs permuted from the 4 OECD countries. For instance, in the 
case of the VC-QGARCH model, the estimated $\rho$ is 0.3490 for the Canada-US pair, whereas it is 0.1230 for the Canada-Italy pair. In general, the estimated $\rho$ is the highest when the US is combined with Canada and lowest when combined with Italy. This is consistent with results from the VC-LGARCH model. Also, the VC-TGARCH model suggests that the correlation between Canada and US is stronger than the Canada-Italy and US-UK pairs. One possible explanation is the different levels of economic integration and bilateral trade intensities between two trading partners. Indeed, Frankel and Rose (1998) have found that OECD countries with closer trade links tended to have more tightly correlated business cycles. According to the 2002 Index of Economic Freedom, the US is Canada's top export and import trading partner, accounting for $86.1 \%$ and 73.7\% of Canada's exports and imports respectively. Also, the US Department of Commerce's Survey of Current Business July 1999 has highlighted that Canada is the top trading partner of the US. Based on the Economic Cycle Research Institute (ECRI)'s chronology, almost all the growth rate cycle peaks and troughs of Canada and the US coincide with each other. For instance, during 1960-1997, 9 peaks in the US occur in the same year as those in Canada. It is therefore not surprising that the co-movements in the conditional volatilities of the Canadian and US IIP are stronger. Furthermore, the correlation between Canada and the US generally tends to fluctuate in a narrower range compared with the correlations of other pairs of countries. Under the VC-LGARCH model, the conditional correlation of Canada-US mainly fluctuates between 0.30 and 0.36, whilst that of Canada-Italy fluctuates between 0.0 and 0.20 .

On the other hand, the correlation between Canada and the UK (0.1024 in the VC-QGARCH model) is weaker. Although the UK is Canada's third largest trading partner, the weaker correlation could be due to the low shares of exports and imports (only $1.5 \%$ and $3.2 \%$, respectively) that the UK accounts for in Canada's total exports and imports. When trade flows are less brisk, macroeconomic shocks are less rapidly transmitted and this may weaken the correlation between countries. However, the conditional correlations for the Italy-UK and UK-US pairs tend to exhibit greater swings and slower mean-reversion. This could be ascribed to the existence of idiosyncratic shocks that are peculiar to the domestic economy of the UK and are not quickly transmitted across countries. This is because they are either confined to the non-tradable sectors or the sluggish components of the economy. Given that the UK's business cycle evolves with less dependency on international influences, the correlation between the UK and the other 2 countries might be weaker than expected. This in turn may explain the larger changes in the conditional correlations over time, as the UK is less correlated with the rest of the world. However, empirical verification of such a conjecture necessitates the study of the microstructure of the domestic economy, which is beyond the scope of this paper.

\section{CONCLUDING REMARKS}

In this paper, we have proposed three bivariate GARCH models to capture the special features of asymmetric conditional volatility and time-varying conditional correlations of business cycles indicators in four OECD countries. Using indices of industrial production as proxies for business cycles indicators, we have detected statistically significant evidence of asymmetric conditional volatility in the UK and the US. In addition, we also found statistically significant evidence of time-varying conditional correlations for most of the countrypairs formed from various permutations of the 4 OECD countries under different specification of the asymmetric GARCH-type models.

The possible explanations of the asymmetric volatility of business cycles may be due to the combined factors of higher risk aversion to downside risk, heterogeneous expectations, supply-side constraints, and precautionary saving motive. When economic agents perceive negative shocks of IIP growth rates, they may incline to curtail private consumption and investment, thereby leading to a further contraction in IIP. The uncertainty associated with deflationary shocks will be greater among economic agents with heterogeneous beliefs about the future outlook of the economy. This may induce risk-averse economic agents to be even more cautious about their consumption and investment decisions. On the other hand, when economic agents perceive expansionary shocks, their desire to increase consumption and investment expenditure is constrained by the potential productive capacity of the economy. As such, the supply-side constraints may be plausible explanations for the asymmetric volatility of real IIP growth in well-developed countries like the US and UK. We may also conjecture that significant volatility asymmetry could be due to the budget deficitto-GDP and/or trade deficit-to-GDP (or aggregate income in general) ratio. This argument is analogous to Black's (1976) "leverage" effect argument. When a negative shock hits the aggregate output/income, these ratios increase. Consumers might save more to make up for the fall in income in order to finance these deficits in future. The government may be induced to cut spending ("disabsorb") so as to improve the trade deficit. Hence, the future aggregate income may fall further, or increase instead because of higher savings. As 
Ho et al., Modeling the Conditional Volatility Asymmetry of Business Cycles in Four OECD Countries

such, negative income or IIP shocks may induce greater volatilities than positive shocks of the same magnitude.

Our findings call for an important need of stronger international policy co-ordination among countries experiencing negative growth shocks. The negative economic disturbances from one country would most likely affect another through the speedy international transmission of business cycles. This in turn will generate adverse impacts on the future volatilities of the real GDP growth rates if the affected countries do not co-operate fast enough to ameliorate such negative shocks.

\section{REFERENCES}

A'Hearn, B., and U. Woitek. "More International Evidence on the Historical Properties of Business Cycles." Journal of Monetary Economics 47 (2001): 321-46.

Bera, A.K, and M.L. Higgins. "ARCH Models: Properties, Estimation and Testing." Journal of Economic Surveys 7 (1993): 305-366.

Blanchard, O.J. and D. Quah. "The Dynamic Effects of Aggregate Demand and Supply Disturbances." American Economic Review 79 (1989): 655-673.

Bollerslev, T. "Generalised Autoregressive Conditional Heteroskedasticity." Journal of Econometrics 31(1986): 307-327.

Bollerslev, T. "Modelling the Coherence in Short-Run Nominal Exchange Rates: A Multivariate Generalised ARCH Model." Review of Economics and Statistics 72 (1990): 498-505.

Choe, J. "An Impact of Economic Integration through Trade: on Business Cycles for 10 East Asian Countries." Journal of Asian Economics 12 (2001): 569-86.

Diebold, F.X., and G.D. Rudesbusch. "Measuring Business Cycles: A Modern Perspective." Review of Economics and Statistics 78 (1996): 67-77.

Ding, Z., C.W.J. Granger, and R.F. Engle. “A Long Memory Property of Stock Market Returns and a New Model.” Journal of Empirical Finance 1 (1993): 83-106.

Engle, R.F. "Autoregressive Conditional Heteroskedasticity with Estimates of the Variance of U.K. Inflation.” Econometrica 50 (1982): 987-1008.

Engle, R.F., and K.F. Kroner. "Multivariate Simultaneous Generalised ARCH.” Econometric Theory 11 (1995): 122-50.

Frankel, J.A., and A.K. Rose. "The Endogeneity of the Optimum Currency Area Criteria." Economic Journal 108(1998): 1009-25.

Hamori, S. "Volatility of Real GDP: Some Evidence from the United States, the United Kingdom and Japan." Japan and the World Economy 12 (2000): 143-52.

Ho, KY, and A KC Tsui. "Asymmetric Volatility of Real GDP: Some Evidence from Canada, Japan, the United Kingdom and the United States.” Japan and the World Economy, 15 (2003): 437-445.

Ho KY, and A KC Tsui. "Analysis of Real GDP Growth Rates of Greater China: An Asymmetric Conditional Volatility Approach.” China Economic Review, 15 (2004): 424-442.

Hong, YM, and J Lee. "One-sided Testing for ARCH Effects Using Wavelets". Econometric Theory 17 (2001): 1051-1081.

Luukkonen, R., and T. Terasvirta. "Testing Linearity of Economic Time Series against Cyclical Asymmetry." Annales d'economie et de statistique 20/21 (1991): 125-42.

Neftci, S.N. "Are Economic Time Series Asymmetric Over the Business Cycle?" Journal of Political Economy 92 (1984): 307-28.

Nelson, D.B. "Conditional Heteroskedasticity in Asset Returns: a New Approach." Econometrica 59.2 (1991): 347-370.

Sentana, E. "Quadratic ARCH Models.” Review of Economic Studies 62 (1995): 639-61.

Sichel, D.E. “Are Business Cycles Asymmetric: A Correction.” Journal of Political Economy 97.5 (1989): 1255-1260.

Terasvirta, T., and H.M. Anderson. "Characterising Non-linearities in Business Using Smooth Transition Autoregressive Models.” Journal of Applied Econometrics 7 (1992): S119-36.

Tse, Y.K. "A Test for Constant Correlations in a Multivariate GARCH Model." Journal of Econometrics 98 (2000): 107-127.

Tse, Y.K., and A.K.C. Tsui. “A Multivariate GARCH Model with Time-Varying Correlations.” Journal of Business and Economic Statistics 20(3) (2002): 351-362.

Zakoian, J. “Threshold Heteroskedastic Model.” Journal of Economic Dynamics and Control 18 (1994): 93155. 